\title{
AFOTE \\ COMPARISON OF SUPPORT INTERVENTIONS DURING A BLENDED COURSE FOR EDUCATORS FROM URBAN AND RURAL SETTINGS
}

\author{
Juliet Stoltenkamp \\ University of the Western Cape, South Africa \\ Martha Kabaka \\ University of the Western Cape, South Africa
}

\begin{abstract}
This research focused on the design and delivery of a blended Professional Development (PD) Program for in-service teacher-educators from both urban and rural settings. The overall purpose of the PD Program was to enhance the educators' Information Communication Technologies (ICT) skills, with emphasis on eTools for supporting teaching-and-learning methodologies. Two groups of teacher-educators undertook the course. A strong facilitation and support approach was maintained throughout the PD Program to encourage self-directed learning. A case study approach was adopted to explore the experiences in the overall implementation and impact of the program. This article reflects on the findings regarding program design and structure; access to resources; impact time management; design of a support structure for the monitoring and evaluation of the program; and educators as self-directed learners using eTools to enhance teaching-and-learning methodologies.

Keywords: South Africa comparative education study, eTools, blended learning, extensive support, Teaching Professional Development (PD), technology support interventions.

\section{Program Background}

The Centre for Innovative Educational and Communication Technologies (CIECT) at the University of the Western Cape (UWC) designed and developed a blended learning course, Designing an Instructional Event, for teacher-educators. The course is registered with the South African Quality Authority (SAQA) at a National Qualification Framework (NQF), Level 6. This research is based on 2 groups of teacher-educators from urban and rural school settings, who engaged in this Professional Development (PD) Program in 2012 and 2013, respectively. Thirty six (36) educators from grades R-12 at Christel House, a private school, in the Western Cape Province; and twenty nine (29) science secondary school teacher-educators from a group of rural
\end{abstract}


schools in the Eastern Cape Province participated in this program. This group was part of the 2013 BEd Honours Program, Faculty of Education at UWC.

Each group received training on ICT with specific focus on eTools. Such skills are relevant as there is still need for innovative approaches to improve the capacity building of teachereducators in South Africa. By the end of the program, each participant was expected to:

1. explain the current trends in eLearning and how they affect the teaching practice;

2. understand the educational philosophies that could inform the online teaching/learning/instructional practices;

3. design a small online teaching/instructional event;

4. understand the need for good structuring of course content for blended learning;

5. select eTools for use in the instructional event according to their pedagogical values and underpinning;

6. understand the roles of an online facilitator and how they affect the learning process; and

7. become self-directed learners.

Before and during the PD Program implementation, participants were made aware of the assessment criteria. Teacher-educators understood they were expected to plan, design and develop a small online teaching/instructional event; and also to actively participate in all program sessions (face-to-face and online phases).

\section{Related Literature}

ICT's in South African Schools. African government institutions are making efforts to ensure that technology for teaching and learning is available at all levels of schooling, a major shift from dependence on support from donor-supported non-governmental organisations (NGO's) who provided mostly small-scale and pilot projects. Governments in Africa are becoming the main the change agents (Glen and Isaacs 2007, 1; eLearning Africa 2013). For example, according to Glen and Isaacs, some governments "have begun to be more proactive in co-ordinating and leading the development of ICT infrastructure in school systems as their ICT policies and implementation plans have taken shape" $(2007,1)$.

A South African E-education white paper indicates a government goal that by 2013 every learner in both rural and urban settings (primary and secondary schools) was expected to be ICT literate (Department of Education 2004, 17). Such policies emphasise the provision of ICT infrastructure to both primary and secondary school levels. Furthermore it aims to bridge the digital divide nationally, thus also meeting the demands to create ICT global villages (Evoh 2007, 64; Oludolapo, 2010). However, these goals are not yet met, as according to recent surveys in Africa only 4,195 schools out of 24,453 schools were connected to the internet (approximately 17\%) (ICT Africa, 2013).

If ICT's are established in the most marginalised schools and communities across Africa, it would lead to much needed social-economic development; as education will become more accessible (Glen and Isaacs 2007, 4; Otieno, 2007). The South African government has stated in its National Policy Framework for Teacher- Education and Development, that the main goal is to ensure that qualified educators are continuously reskilled and provided with the necessary 
professional development support. These reskilling processes should include relevant ICT skills and resources for learners and educators across South Africa (Steyn 2010, 212-213).

PD courses in ICT for various target groups such as staff in Higher Education Institutions (HEIs) and the private sector have also received attention across the globe. This attention on educators resulted in courses that they may benefit from which provide continuous engagement in PD ICT skills courses through a blended learning approach (Bath and Bourke 2011; Ifeoma and Olusola 2013).

Blended Learning Courses. Blended learning also termed hybrid or mixed mode learning is a term that is constantly evolving, hence researchers have indicated a state of challenges due to limited "distinction between hybrid and blended courses". Moreover different authors commonly agree that there are four definitions of blended courses: the application of both face-to-face and instructional technology in teaching; the use of various forms of technology, such as CD-ROMs with web-based technology for teaching; the use of pedagogical approaches, such as constructivism and behaviorism even in the absence of learning technologies; and the blend of instructional technology for the completion of specific tasks (Owston, Murphy, and Lupshenyuk 2008, 201-202; Koller, Harvey, and Magnotta 2006).

The first blended learning approach is specifically of significance in education as participants are able to benefit from the opportunities provided in both the face-to-face and online environments. Hence, this interaction creates a state of balance in relation to the access to experts (teachers) and information and knowledge (Osguthorpe and Graham 2003, 228; Dziuban, Hartman, and Moskal 2004).

During implementation of this blended learning approach, participants require critical support. Therefore, during the design, certain questions need to be posed: "How will students taking blended courses access support? Will there be 24 hour, 7 day per week help desk support?" (Diaz \& Strickland 2009). Additionally, recent research conducted in a United States high school indicated that educators require support through blended courses to meet expected 21st-century skills in classrooms. The research recommended that more focus should be placed on those teachers-educators who have no previous ICT skills (Pape 2010).

Intensive design and implementation processes of blended course. This learning approach entails intensive processes. Research shows that this approach has recently received more attention than conventional face-to-face; or purely online learning (Precel, Eshet-Alkalai, and Alberton 2009). However, there seems to be a lack of research on establishing what blended learning approaches categorically entail, which could offer clarity around the standards for effective course design. This means that blended learning approaches still lack "a coherent body of research that unequivocally demonstrates learning benefits over traditional modes of instruction" (Smythe 2012, 1; Johnson and Marsh 2013).

Such observations indicate the need for serious planning of blended learning courses in order to enable easy implementation and delivery. This avoids the mere "flip" of the classroom from traditional to online without effective preparation (McGee 2013). Other issues which require attention include: redesign to meet the identified needs of unique target groups; the design of 
activities that enable interaction whereby students are able to interact by sharing course content; and the provision of essential support .Therefore, an instructional and developmental approach that fails to pay attention to these issues at the planning stages may lead to challenges that may hinder both the facilitators and course participants (Rowley, Bunker, and Cole 2002). This research project explored the intensive experiences of the implementation of the blended design through a PD Program for educators by implementing case study methodology.

\section{Methodology}

A case study methodology was adopted to retrieve findings related to the engagement of educators within the PD Program: Designing an Instructional Event. These educators teach in schools situated in an urban and various rural settings, respectively: 36 educators from Christel House, a private secondary school in the Western Cape; and 29 science educators from various schools in the Eastern Cape, Mthatha, including: St. James Senior Secondary School (SSS); Khanya Naledi Combined School; Ntukayi SSS; Nomaka Mbeki SSS; and Msobomvu SSS. The educators from Christel House represented various teaching disciplines from Grades R to 12; whereas the educators in the Eastern Cape were Science secondary school teachers. The 65 participants within this study were full-time working educators and represented a mix of 41 females and 24 males.

A Qualitative Research Design was adopted in which data was collected first by making use of three (3) different types of open-ended questionnaires including, prior-learner; monitoring; and an evaluation. These questionnaires broadly covered the following areas of: ICT skills/eSkills; competencies and attitudes; relevance of the face-to-face interactions; views related to group work; time management skills; access to ICT resources at the institutional and individual levels; and teachers' prior professional development programs. Second, the data was analysed from individual participants' submissions and engagement in online discussion forums. Finally, observations of presentations on the last day of the face-to-face phase, where all educators were expected to showcase the use of eTools for teaching-and-learning purposes. The following discussion reviews the factors that impacted the design, development and delivery of this PD Program.

\section{Discussion}

The researchers of the PD Program provided detailed comparison of the main themes highlighted during the data analysis process that included the program's design and structure ; critical faceto-face interaction; access to resources impact on time management; design a support structure for the monitoring and evaluation of the program; educators as self-directed learners; eTools to enhance teaching-and-learning methodologies; and barriers that hindered commitment to the program. Lastly, the researchers provided a comparative summary matrix framework of the factors which influenced the delivery of the blended learning program.

Program design and structure. A scaffolding approach for working educators was adopted, in which the course was implemented in two (2) phases. The educators were expected to engage in a face-to-face training intervention; and four (4) weeks within an online environment. This approach enabled participants to complete related tasks, as they were motivated and guided through milestones. The guides were available through email, discussion forums, instructional manuals and multimedia screencasts. This blended learning approach was beneficial, as the 
group of educators, specifically those in the rural settings, experienced grave challenges due to limited infrastructure (at times no internet available for an entire week). Furthermore, it should be noted that due to these challenges the PD Program was redesigned to include an additional face-to-face phase for the educators in the rural settings. Notably, the educators situated in the urban setting had the opportunity to engage in the face-to-face phase in a fully functional computer lab at UWC. They were also able to complete the milestones without major challenges.

It is important that the design and structure of a blended learning program should continuously be revised and redesigned according to the target group and context. The following themes highlight the experiences of the educators and facilitators as they progressed through the structured PD Program.

Critical face-to-face interaction. Seventy percent (70\%) of urban respondents indicated that the hands-on, supportive face-to-face phase was valuable and relevant, even though they had completed their milestones without major challenges. This was compared to only $24 \%$ of the responses from educators in the rural setting who indicated face-to-face interaction as always critical. It was identified as especially necessary for adult learners to clarify tasks and related milestones. Even though there was disparity in the indicated need for face-to-face interaction, facilitators' observations during the face-to-face phases tracked a great demand for assistance by all $(100 \%)$ of the educators (both groups/settings) as they engaged with the various eTools.

Research has provided numerous reasons why face-to-face interaction during learning is relevant, as it provides an opportunity for teacher and learner interaction, especially to seek clarity and share ideas (Bejerano 2008). It is therefore critical to provide the necessary support during face-to-face interactions, as it minimises the situation whereby misassumptions are made concerning adult learner needs. Moreover, there is a need for skilled human capacity in order to support intensive blended learning programs. The teacher or facilitator roles cannot be disputed in learning, they are expected to "encourage and motivate, guide and monitor progress, give feedback, boost confidence, and maintain motivation” (Marsh 2012, 8).

Access to resources as impacts time management. It was noted that access to necessary resources affected participants from both settings either negatively or positively. It was found that $100 \%$ of the educators from the urban setting finalised their course milestones within the stipulated timeframes. This starkly contrasted with the outcome that none of the educators in the rural settings completed milestones in the stipulated timeframes. For example 16 rural participants did not respond to any of the discussion forum topics within the given time period. Most of these educators requested extended timeframes for the submission of tasks. Research indicates that the lack of relevant technology infrastructure is a major barrier that hindered access to skills among students and educators (UNESCO Institute for Statistics 2006; Hennessy and Onguko 2010).

The educators from the urban setting had acess to a fully equipped computer lab and a technical support member at their place of work (school); and 50\% had access to personal internet connected computers at their homes. In contrast, the educators from the rural setting encountered major access challenges. Only 18 rural educators had access to the internet at home; only 6 had access to computer labs within their working environments; 9 had internet acess at work; and 7 
had digital projectors/interactive whiteboards. Moreover, none of the rural educators had access to a fully equipped lab facility at their respective schools.

Educators who enrolled for this PD Program were expected to engage in some pre-reading and utilize content related to their subject area, and use technical resources, such as smart phones, $3 \mathrm{G}$ cards, laptops, and flash-drives. Most of the educators (90\%) from the rural setting did provide their personal resources. Furthermore, the training facility in the rural setting, a computer lab, was equipped with desktop computers. However it had no internet connectivity, as the facilitators were informed that the entire surrounding Mthatha area had no network access because the network cabling system was "stolen and Telkom is refusing to come out again, as it was the second time that the cables were removed."

The participants were shown how to access their online teaching events (basic structures) via mobile devices. However, only 4 participants were willing to make use of their smart mobile phones to access the online environment, as it required that they make use of their own data bundles. Sasson (2008) notes that failure to manage time properly may lead to the failure of a course, yet in this case the ICT resources that were the pillar to successful adoption by both educators and students of online and multimedia education were not readily available. Therefore Bingimlas (2009) instructs that institutions must ensure that all resources are available so as to enhance teaching and learning.

Design a support structure for the monitoring and evaluation of the program. Both groups of educators were supported and monitored by the facilitators, throughout the PD Program. A dedicated support structure was designed prior to program delivery. For example, during the online phase, each facilitator was assigned to a number of participants to support, monitor, and assess milestones. This support structure was critical as the CIECT team delivered the program parallel to the daily operations of UWC.

The online phase of the PD Program provided substantive support for the educators and this was enhanced with constant communication. The facilitators observed the need for extensive support for the educators in the rural setting, specifically in relation to the completion and submission of productions which required more advanced eSkills, namely, the creation and application of a picture collage and a digital story. Furthermore, this extensive support process included constant communication with educators via emails and discussion forums. These included the creation of instructional manuals with relevant text and graphics, by the facilitators, for the completion of the final prototype (the creation of a small online teaching event); and the related productions: (i) the structure and design of an online course divided into manageable mini-instruction sheets (12); (ii) engaging in 2 main discussion forums which were further sub-divided into 11 subtopics; and (iii) creation of a digital story and photo-collage.

Despite the design of an extensive support structure, the facilitators observed that the educators in the rural settings demonstrated a worrisome level of commitment and participation. For example: (i) Learning Pathway 2A: Creation and application of collages and digital stories resulted in only $64 \%$ of rural participants responding to discussion topics and submitting related milestone tasks; (ii) Learning Pathway 2B: Completion of final assessment task resulted in 29\% of participants not responding or submit this task. 
Dedicated support structures are necessary in blended learning programs, for example in UWC the CIECT team "is tasked with these responsibilities since it was established to provide a structure for the implementation of integrated, holistic support and development for the institution" (Stoltenkamp, Kies, and Njenga 2007, 146). Other writers also argue that blended learning is characterised by teamwork between course participants and the support team (Bailey, Ellis, Schneider, and Ark 2013).

Educators as self-directed learners. This research found that educators from the urban setting presented themselves as self-directed learners, i.e. in relation to the completion of guided milestone activities. Ninety nine (99\%) of these participants were self-motivated to accomplish milestones as expected. Only 1 educator required an extension to complete the final submission, the development of a prototype: a small online teaching event.

In contrast, the rural educators required more assistance in relation to completing milestones during the online phase of the program. Most of these educators, $57 \%$, required continuous encouragement and support during the online phase in order for them to meet the stipulated submission dates. This led to an extension of submission deadlines, however, despite the support and extension of deadlines, research findings indicated that $31 \%$ did not manage to respond to discussion forums nor submit tasks on the online phase.

The design of the PD Program as discussed above indicated that learners, even though they are adult working professionals, still require structure and order. A learning pathway, specifically milestone online mini-tasks, was used to guide and facilitate the process of self-directed learning. Furthermore, the facilitators observed the need for basic ICT skills attainment by participants, prior to engagement in more interactive blended learning programs. Likewise, research indicates that age also impact ICT adoption, as older adult learners demonstrated more resistance to participating fully in the program. This finding aligns with similar findings in Tedla's work (2012).

eTools enhance teaching-and-learning methodologies. The 2 groups of educators expressed similar responses related to the application of eTools in their specific disciplines. These responses were deliberated within discussion forums. The educators were expected to demonstrate their understanding and application of specific eTools during the presentation phase of the program. Visiting principals and sponsors were able to view these presentations on the last of day of the face-to-face phase.

Some of participant responses retrieved from the discussion forums regarding the effective use of eTools within their specific disciplines included:

To supplement our high-touch teaching (chalk and talk and face to face in class) with a high-tech approach (eLearning tools via internet, etc.) will surely enhance teaching. Teaching should be beyond the walls of the classroom. The learners' intelligence should be measured by the skilled help of the educator. Hence to add more colour and value but not substitute my teaching all together through 
examples like: Audacity, PowerPoint Presentation, Google Blogger, aTubeCatcher, Picasa, Digital Photo Story and Wordle. - Urban Educator

And this email exchange provides representative feedback from a Rural Educator participant:

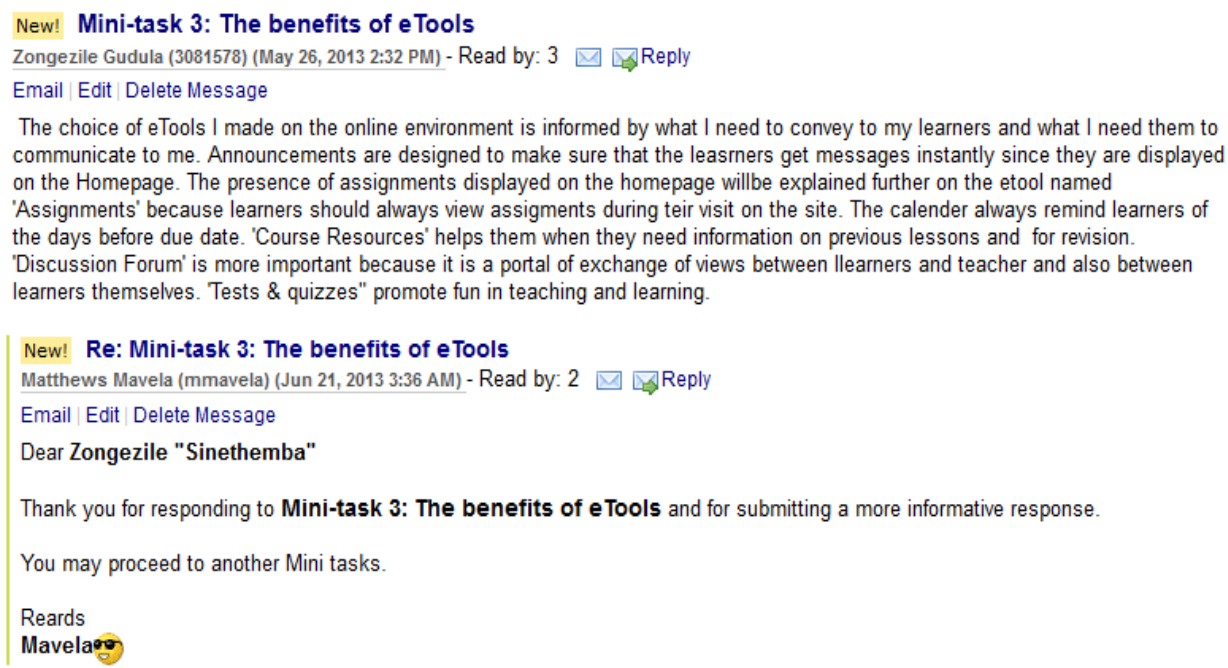

The educators' ability to apply such eTools in their teaching discipline is in line with the growing demands of education which requires the society, to take fully utilize computer technology to improve teaching and learning processes.

Personal barriers which hinder program commitment. In relation to personal educator-level barriers, the facilitators observed, during the face-to-face phases that some teachers from both groups lacked the confidence to complete basic activities by themselves and would repeatedly seek assistance. Buabeng-Andoh wrote broadly on personal barriers as major "factors influencing teachers' adoption and integration of information and communication technology into teaching" $(2012,2)$.

One educator even expressed resistance to the adoption of eTools for teaching and learning purposes. This resistance was reported in other studies, for example, Haydn indicated that at the University of East Anglia teachers' attitudes had improved from previous "surveys several years ago which suggested that there were various forms of teacher resistance to ICT" $(2009$, np). This resistance posed a barrier which hindered personal commitment to the program and its related milestones.

This resistance was linked to the concern by some educators that they did not have the personal time to commit to the PD Program. In the prior learner questionnaire, the majority of educators had committed 0-7 hours per week for personal studies. However, the research indicated an actual commitment of only 2-4 hours per week. A time constraint is one of the major causes of failure of adult learners' for "not being able to undertake learning" (OECD 2005, 5). 
Furthermore, school level barriers, as indicated by the educators, also impacted personal commitment. In this case, educators in the urban setting, had access to the necessary infrastructure within their school environment. However, only 9 educators from the rural school settings had access to technical support. Nineteen rural educators lacked resources such as digital projectors and interactive whiteboards; while only 9 educators had computers for student use in their classrooms. Thirteen educators had no desktop computers for student use within the school. Research identifies time and access to necessary infrastructure as one of the critical barriers to ICT adoption for teaching and learning (Gay 1997; Bingimlus 2009). Such barriers are not exceptional in the South African context, as research states that educators in other areas of South Africa face similar barriers in their efforts to adopt and integrate ICT in teaching and learning (Goktas, Yildirim, and Yildirim 2009; Sharma 2003).

\section{Conclusion}

This ICT research study reflected on the engagement of two teacher educator groups in a blended design program. The overall purpose of this Professional Development Program was to enhance the educators' Information Communication Technology (ICT) skills, with an emphasis on eTools to support teaching and learning methodologies.

This research originated from two previous publications related to the PD Program implementation and support structure. This article highlighted the following comparative areas (i) program design and structure ; (ii) critical face-to-face interaction ; (iii) access to resources impact on time management; (iv) design of support structure for the monitoring and evaluation of the Program; (v) educators as self-directed learners; (vi) eTools enhancement of teaching and learning methodologies; and (vii) personal barriers which hinder ICT PD Program commitment.

The researchers recommend the adoption of this blended learning PD Program as one approach to meet the goals of the South African White Paper on PD for teacher educators specifically ICT skills. Such blended learning programs allow fulltime working professionals an opportunity to attain necessary skills. Furthermore, the researchers recommend the government and interested organisations (private sector and non-governmental organisations) invest more in ICT equipment, infrastructure and training for educational purposes, especially within rural settings.

Acknowledgement: Researchers wish to acknowledge the CIECT team for their commitment in facilitating the Professional Development Program.

\section{REFERENCES}

Bailey, J., Ellis, S., Schneider, C. \& Ark, T.V. (2013). Blended learning implementation guide. Version 1.0. Retrieved from http://net.educause.edu/ir/library/pdf/CSD6190.pdf.

Bath, D. \& Bourke, G. (2011). The blending of blended learning: An experiential approach to academic staff development. Retrieved from http://www.ascilite.org.au/conferences/hobart11/downloads/papers/Bath-concise.pdf.

Bejerano, A. (2008). Face-to-face or online instruction? Face-to-Face is better. Retrieved from http://www.natcom.org/CommCurrentsArticle.aspx?id=884. 
Bingimlas, K. A. (2009). Barriers to the successful integration of ICT in teaching and learning: A review of literature. Eurosia Journal of Matematics, Science and Technology Education, $5,235-245$.

Buabeng-Andoh, C. (2012). Factors influencing teachers' adoption and integration of information and communication technology into teaching: A review of the literature. International Journal of Education and Development using Information and Communication Technology (IJEDICT), 8, 136-155.

Department of Education (2004). Draft White Paper on E-education: Transforming Learning and Teaching through ICT. Pretoria: Republic of South Africa.

Dziuban, C., Hartman, J., Moskal, P., Sorg, S. \& Truman, B. (2004). Three ALN modalities: An institutional perspective. In Bourne, J. \& Moore, J.C. (Eds.), Elements of Quality Online Education: Into the Mainstream (pp. 127-148). Needham, MA: Sloan Center for Online Education.

Diaz, V. \& Strickland, J. (2009). EDUCAUSE Learning Initiatives, Unit 7: Implementing Blended Learning. Retrieved from http://net.educause.edu/ir/library/pdf/ELI80077.pdf.

Egenti, M. N. \& Omoruyi, F. E. O. (2011). Challenges of Women Participation in Continuing Higher Education Programme: Implications for Adult Women Counselling and Education. African Journals Online, Vol. 4(1).

Elletson, H. and Burgess, A. (eds.) (2015). The eLearning Africa Report 2015, ICWE: Germany.

Evoh, C. J. (2007). Policy networks and the transformation of secondary education through ICTs in Africa: The prospects and challenges of the NEPAD e-schools initiative. International Journal of Education and Development using Information and Communication Technology (IJEDICT), 3, 64-84.

Gay, S. M. (1997). Teaching with Technology: A Case Study of Teachers' Perceptions of Implementing Computers into the Classroom. Unpublished Dissertation. Lincoln, NE: University of Nebraska.

Glen, F. \& Isaacs, I. (2007). Survey of ICT and Education in Africa. ICT and education series. Retrieved from http://www.infodev.org/infodevfiles/resource/InfodevDocuments 353.pdf.

Goktas, Y., Yildirim, S. \& Yildirim, Z. (2009). Main barriers and possible enablers of ICTs integration into pre-service teacher education programs. Educational Technology \& Society, 12, 193-204.

Hennessy, S. \& Onguko, B. (2010). Developing the use of information and communication technology to enhance teaching and learning in East African schools: Review of the 
literature. Retrieved from

http://www.educ.cam.ac.uk/centres/cce/publications/CCE_Report1_LitRevJune0210.pdf.

Haydn, T. (2009). Teacher education and ICT: Some points for consideration from the UK. UK: University of East Anglia. Retrieved from http://www.oecd.org/edu/ceri/41674026.pdf.

Ifeoma, E. R. \& Olusola, E. (2013). The teachers and the use of ICT for professional development. ICT for Africa. Retrieved from http://ictforafrica.org/attachments/section/4/ict4africa2013_submission_34.pdf.

Johnston, C. \& Marsh, D. (2013). The laureate English program taking a research informed approach to blended learning. Higher Learning Research Communications, 3.

Koller, V., Harvey, S. \& Magnotta, M. (2006). Technology-based learning strategies. Oakland, CA: Social Policy Research Associates Inc. Retrieved from http://www.doleta.gov/reports/papers/TBL_Paper_FINAL.pdf.

Marsh, D. (2012). Blended Learning Creating Learning Opportunities for Language Learners. Cambridge, MA: Cambridge University Press.

Organisation for Econominc Corporation and Development. (2003). Beyond rhetoric: Adult learning policies and practices report. Retrieved from http://www.edra.gr/pdf/9103011E-OECD.pdf.

Osguthorpe, R.T. \& Graham, C.R. (2003). Blended learning environments: Definitions and directions. The Quarterly Review of Distance Education, 4, 227-233.

Osunkunle, Oluyinka O. (2010). Bridging the digital divide and the impact of new media technologies on development in South Africa: New achievements (pp. 373-387). In Soomro, Safeeullah (Ed.), Technology Education and Development. Rijeka, Croatia: InTech.

Owston, R. D., Sinclair, M. \& Wideman, H. (2008). Blended learning for professional development: An evaluation of a program for middle school mathematics and science teachers. Teachers College Record, 110, 1033-1064.

Rowley, K., Bunker, E. \& and Cole, D. (2002). Designing the right blend: Combining online and onsite training for optimal results. Performance Improvement, 41, 24-34.

Sharma, R. (2003). Barriers in using technology for education in developing countries. Computers \& Education, 41, 49-63.

Steyn, G.M. (2010). Educators' perceptions of continuing professional development for teachers in South Africa: A qualitative study. African Education Review, 7, 343-365. 
Stoltenkamp, J., Kies, C. \& Njenga, J. (2007). Institutionalising the elearning division at the University of the Western Cape (UWC): Lessons learnt. International Journal of Education and Development using Information and Communication Technology (IJEDICT), 3, 143-152.

Stoltenkamp, J., Kabaka, M. \& Kies, C. (2013). Course for educators: designing an instructional event. In Proceedings of EDULEARN 13 Conference 1-3 ${ }^{\text {rd }}$ July. Bercelona, Spain: EduLearn.

Tedla. B.A. (2012). Understanding the importance, impacts and barriers of ICT on teaching and learning in East African countries. International Journal for e-Learning Security (IJeLS), 2.

Virginia Common Wealth University. (u.d). Online teaching and learning resource guide. Center for Teaching Excellence. Retrieved from http://www.vcu.edu/cte/resources/OTLRG/01_06_BlendedClasses.html. 